1. Lecturer,

Institute of Rural Home Economic, Univ. of Agri., Faisalabad

2. Professor,

Institute of Agri.

Extension and Rural Development Univ. of Agri., Faisalabad

3. Assistant Professor, Institute of Agri.

Extension and Rural Development Univ. of Agri., Faisalabad

4. Lecturar,

Institute of Rural Home Economic, Univ. of Agri., Faisalabad

5. Associate Professor,

Institute of Agri. Univ. of Agri., Faisalabad

Correspondence Address:

Dr. Ayesha Riaz

Lecturer,

Institute of Rural Home Economic, Univ. of Agri., Faisalabad
Extension and Rural Development,

\section{THE ROLE OF PUNJAB RURAL SUPPORT PROGRAMME IN PROVIDING HEALTH FACILITIES TO RURAL WOMEN; A CASE STUDY OF DISTRICT FAISALABAD}

\author{
Dr. Ayesha Riaz1, Dr. Sher Muhammad², Dr. ljaz Ashraf ${ }^{3}$, Dr. Aisha Siddique ${ }^{4}$, Dr. Khalid Mahmood Ch. ${ }^{5}$
}

ABSTRACT... Despite the fact that women account for more than half of the total world population, they are still not considered equal to men. The health of rural women in Pakistan is very poor because of the lack of health services and competent health workers. Besides government health centres, hospitals and many Non-Governmental Organizations (NGOs) are also working in the rural areas for providing social services to rural women. Punjab Rural Support Programme is also working for socio-economic empowerment of rural women. PRSP began to provide health facilities to the poor people in villages through Basic Health Units (BHUs). Objectives: To analyze the role of PRSP in providing health facilities to women in rural area. Design: A multistage simple random sampling technique was used for the study. Setting: District Faisalabad. Material \& Methods: The population for the study consisted of rural women only who were members of the Community Organizations (COs) of PRSP. Out of the eight towns of district Faisalabad, four towns which cover rural areas (Samundri, Iqbal town, Jaranwala, and Chak Jhumra) were selected. Four field units of PRSP are working in these four towns i.e. Salarwala in Chak Jhumra, Satiana in Jaranwala, Khidarwala in Samundri, and Dijkot in Iqbal Town. These field units had 214, 203, 170 and 238 female COs, respectively. A sample of $10 \%$ COs was selected from each field unit randomly. Thus the total selected COs were 82 . Five members from each $\mathrm{CO}$ were selected at random. In this way the total sample size for the study was 410 respondents. A reliable and validated data collection instrument consisting of open and close ended questions was used. The data were analyzed using SPSS. It was concluded that respondents were satisfied with certain facilities like availability of female doctors in BHUs, availability of medicines and availability of competent and qualified paramedics. Provision of basic tests (blood, sugar, pregnancy and haemoglobin etc.) was very weak area which needed much improvement. Conclusions: It was also concluded that respondents were satisfied with the behaviour of staff at BHUs. However, provision of basic medical equipment needed attention from the authorities.

Article received on:

$16 / 05 / 2014$

Accepted for publication: 24/07/2014

Received after proof reading: $16 / 10 / 2014$

Key words: $\quad$ Punjab Rural Support Programme, Basic health unit, rural women

Article Citation: Riaz A, Muhammad S, Ashraf I, Siddique A, Ch. KM. The role of Punjab rural support programme in providing health facilities to rural women; a case study of district Faisalabad. Professional Med J 2014;21(5):1033-1038.

\section{INTRODUCTION}

Despite the fact that women account for more than half of the total world population, they are still considered inferior to men and are treated as second class citizens in every aspect of life. According to UNICEF (2004) ${ }^{1}$, of the world's 875 million illiterate adults, two thirds are women. Similarly over 110 million of the world's children are not attending school and two thirds of them are girls. Almost 14000 females die due to pregnancy related causes; moreover one in every three women is a victim of gender based violence. In spite of all the contributions in every sphere of life women have mostly been deprived of their true status and this scenario is at its worst in developing countries. Singh \& Singh $(2005)^{2}$ narrated that in the South Asian countries like Bangladesh, Nepal, Pakistan and India, the state of women is not enviable. In these countries, gender bias is so deep-rooted that it has become social order and patriarchy is traditional. Poverty, ill-health, unemployment, segregation and violence prevail in all walks of life. In all these countries, women do not have adequate access to health and education facilities. According to WHO (2009) ${ }^{3}$ out of around half a million maternal deaths that occur every year in the world, almost $99 \%$ happen in developing countries. Women's health during 
the reproductive years (between age of 15 and 49) are related to not only women themselves, but also has a strong impact on the health and development of the children. Complications of pregnancy and childbirth are the main reasons of death in young women (between the age of 15 and 19 years) in developing countries. Worldwide, the foremost cause of death among females of reproductive age is HIV/AIDS. In developing countries most vital risk factors for death and disability in the reproductive age are unsafe sex and lack of contraception. The result of these factors includes unwanted pregnancies, complications of pregnancy and childbirth, unsafe abortions and sexually transmitted infections. Violence is another noteworthy danger to women's reproductive and sexual health. It can result in chronic health problems and mental illhealth.

The condition of women in Pakistan in general has been horribly adverse since the creation of the country. Their plight has not got any better today and they are still considered third rate citizens. Gender discrepancies in the country are very severe. Deeply rooted cultural limitations prevent Pakistani women from performing their active role in the progress of society. Illiteracy, limited access to employment opportunities and limited access to health facilities are some of the important challenges faced by women in Pakistan. Women are also faced with problems like cultural barriers, traditions, sufferings and exploitation ${ }^{4}$.

In Pakistan the issue of women health is nota matter of great concern because of gender discrimination and lack of respect for women in the society. Due to the cultural and traditional taboos, women were never given equivalent status in the society. In the country three females per hour die due to the complications associated with pregnancy. Anemia is also very common in women especially in low socio economic class. Iron deficient diet is the basic reason for this. Improper sewerage system and lack of clean water is a reason of worm infestation which is another reason of iron deficiency in women in rural areas. Moreover majority of basic health units in rural areas are not very serviceable and functional ${ }^{5}$. In Pakistani society due to the traditional taboos and absolute poverty, most of the women get no treatment of breast cancer. Radiotherapy and chemotherapy are very expensive, almost out of the reach of poor women. Another major problem is that majority of women is illiterate and has no knowledge about the disease ${ }^{6}$. According to Kazmi (2008) ${ }^{7}$, there is a close link between women health and their low status in society. Even obvious differences among health status of women and men are noticeable in Pakistani culture. Various factors including lack of knowledge about women's health necessities, illiteracy, low social status and cultural constrains and restrictions on women are the reasons for women's low health standard in the country. There is lack of awareness and education among male and females about family planning which consequently affects the health of mother and her child.

The health of rural women is very poor because of the lack of health services and competent health workers. Poor health and early death of mothers affect the health of children; productivity at household level and in turn country's economy. Improvement in the reproductive health of women by using contraceptives and reasonable gaps between pregnancies cannot only improve female health but is a good way to control population and provide women more time to utilize in economic activities. Malnutrition is the most important health problem that excessively affects females and girls in Pakistan. The children die between the ages of 1 to 4 , majority of them is girls. The mortality rate of females is $12 \%$ higher than of males. This is mainly due to the low social status of women and girls who are given less food than males and have to face hindrances for the attainment of health care. Many women and girls often die of communicable diseases such as tuberculosis and tetanus. Poor living conditions and low social status of females are the reasons for the high occurrence of communicable ailments and malnutrition ${ }^{8}$. White $(2001)^{9}$ revealed the health situation in Pakistan. Mostly women and children are under constant health burdens in the country. Fundamental reasons for this situation are low status of women 
in the society, unjust living conditions and lack of educational and economic opportunities. Despite family planning programs, Pakistan has faced rapid population growth since beginning. Total fertility rate is very high (5 pregnancies per woman). Still pregnancy and delivery are risky. Mostly women do not seek antenatal care during pregnancies. Most of the births are attended by untrained personnel, a very few (19\%) of births are attended by trained personnel. In Pakistan the figures of Maternal Mortality Ratio (MMR) are $340 / 100,000$ live births. This situation demands proper education of women using all possible means.

Besides government health centres and hospitals many Non-Governmental Organizations (NGOs) are also working in the rural areas for providing social services to rural women. The NGOs act as a catalyst by providing information, highlighting problems, challenging policies, providing support and cohesion to the rural women. At present NGOs are playing a very important role in providing services to rural women regarding education, poverty alleviation, family planning, health related issues, conservation of environment and development of non-formal education. Punjab Rural Support Programme is one of the many RSPs which are working in Pakistan. Its main aim is to mobilise the community, build capacity and to run operations that encourage socio-economic empowerment. The prime function of PRSP is the social mobilisation of communities. The main function of social mobilisation is to help equip the less privileged people fight poverty. The different programmes that PRSP has formulated aim at development of the human capital, organisation of the community, social sector service delivery, provision of credit, giving awareness about ways of saving, formation of capital and connection with different NGOs, private organisations and government departments ${ }^{10}$.

PRSP began to provide health facilities to the poor people in villages through Basic Health Units (BHUs). Therefore, the present study is designed to analyze the role of PRSP in providing health facilities to women in rural area. The results of the study would be helpful to identify the strengths and weaknesses of development measures taken by the PRSP for rural women regarding their health. Furthermore, the study would be helpful in devising a future strategy for developing better grounds in context of rural women health.

\section{MATERIALS AND METHODS}

The present study was conducted in district Faisalabad. The results of the study would be advantageous to identify the strengths and weaknesses of PRSP in catalyzing the process of empowerment and to propose measures for further improvement. The population for the study consisted of rural women only who were members of the Community Organizations (COs) of PRSP. A multistage simple random sampling technique was used for the study. Out of the eight towns of district Faisalabad, four towns which cover rural areas (Samundri, Iqbal town, Jaranwala, and Chak Jhumra) were selected. Four field units of PRSP are working in these four towns i.e. Salarwala in Chak Jhumra, Satiana in Jaranwala, Khidarwala in Samundri, and Dijkot in lqbal Town. These field units had 214, 203, 170 and 238 female COs, respectively. A sample of $10 \%$ COs was selected from each field unit randomly. Thus the total selected COs were 82 . Five members from each $\mathrm{CO}$ were selected at random. In this way the total sample size for the study was 410 respondents. A reliable and validated data collection instrument consisting of open and close ended questions was constructed keeping in mind the research objectives. A five point Likert scale was used to assess the respondent's perception regarding various aspects. Every possible measure was taken to secure valid and reliable data. The data were analyzed using SPSS. Univariate analysis was used which includes the frequencies, percentages and means of different variables. The rank order was determined on the basis of the weighted score. In order to know the relative ranking of different variables, the relative scores were computed by multiplying the score value allotted to each category of the scale with the frequency counts.

\section{RESULTS AND DISCUSSION}




\section{Health Facilities}

Frail infrastructure and imperfect distribution systems in developing and low income countries set hurdles in access to health services, particularly in rural areas. Government health centres and hospitals are relatively few and widely dispersed. On the other hand private-sector health centres often favour urban areas. In the absence of a concrete heath system, strengthening community based health services help in providing more reasonable access to health services ${ }^{11}$. There is a dearth of health facilities in rural areas especially for women. It is generally assumed that majority of health centres lack availability of doctors and medicines. Therefore respondents were asked about their views regarding the health facilities and their responses were ranked in Table I. The data show that availability of female doctors in the BHUs (mean=3.49) was ranked 1st and fell in between satisfactory and good categories but tended toward good category. Availability of medicines (mean=3.33) and competent and qualified paramedics (mean=3.10) fell in between satisfactory and good categories but tended toward satisfactory category and were ranked 2nd and 3rd, respectively. However, provision of basic medical equipment (x-ray machine, blood pressure apparatus etc.) was ranked 4th with mean value 2.52 and fell in between fair and satisfactory categories but tended toward satisfactory category. Provision of basic tests (blood, sugar, pregnancy, haemoglobin etc.) with mean value 2.41 was ranked 5 th and fell in between fair and satisfactory categories but tended toward fair category. It can be concluded that respondents were satisfied with the

\begin{tabular}{|c|c|c|c|c|}
\hline Health facilities & Rank order & Weight score & Mean & Std. Deviation \\
\hline Availability of female doctors in the BHUs & 1 & 492 & 3.49 & 0.72 \\
\hline Availability of medicines & 2 & 466 & 3.33 & 0.89 \\
\hline Availability of competent and qualified paramedics & 3 & 419 & 3.10 & 0.84 \\
\hline $\begin{array}{l}\text { Provision of basic medical equipment (x-ray machine, } \\
\text { blood pressure apparatus etc.) }\end{array}$ & 4 & 353 & 2.52 & 0.97 \\
\hline $\begin{array}{l}\text { Provision of basic tests (blood, sugar, pregnancy, } \\
\text { haemoglobin etc.) }\end{array}$ & 5 & 337 & 2.41 & 1.03 \\
\hline \multicolumn{5}{|c|}{$\begin{array}{l}\text { Table-I. Rank order, means and standard deviation of respondents' observation based on the health facilities } \\
\text { provided by PRSP } \\
\text { ale: } \quad 1=\text { Poor, } 2=\text { Fair, } 3=\text { Satisfactory, } 4=\text { Good, } 5=\text { Excellent, } X=\text { No response }\end{array}$} \\
\hline
\end{tabular}

availability of female doctors in BHUs, availability of medicines and availability of competent and qualified paramedics. However, the provision of basic medical equipment like $\mathrm{x}$-ray machine and blood pressure apparatus and provision of basic tests (blood, sugar, pregnancy and hemoglobin were the areas which needed improvement.

\section{Strengths of Health Facilities}

Health is one of the basic fundamentals for normal human existence. In Pakistan the health system is not fully established to provide sufficient services to people. There are many factors responsible for the ineffectiveness of health sector such as scarcity of funds, inadequacy and limited access to health services, extreme poverty and deficient health infrastructure ${ }^{12}$. The ranking of strengths of health facilities provided by PRSP is presented in Table-
II which show that strength like behaviour of staff is good was ranked 1st with mean value 3.74 and fell in between the categories of somewhat agree and agree but tended toward agree category. All other statements like access to female doctors is easy, adequate staff is available (doctor, nurse etc.), supply of medicines is enough, location of $\mathrm{BHU}$ is convenient and availability of medical supplies (syringes, bandages etc.) is adequate fell in between the categories of somewhat agree and agree but tended toward somewhat agree category and were ranked from 2 nd to 6 th with mean values 3.48, 3.31, 3.29, 3.28 and 3.01, respectively. 


\begin{tabular}{|l|c|c|c|c|}
\hline Strengths & Rank order & Weight score & Mean & Std. Deviation \\
\hline Behavior of staff is good & 1 & 520 & 3.74 & 0.62 \\
\hline Access to female doctors is easy & 2 & 480 & 3.48 & 0.71 \\
\hline Adequate staff is available (doctor, nurse, etc) & 3 & 463 & 3.31 & 0.88 \\
\hline Supply of medicines is enough & 4 & 461 & 3.29 & 0.91 \\
\hline $\begin{array}{l}\text { Location of BHU is convenient } \\
\text { Availability of medical supplies (syringes, bandages, } \\
\text { etc) is adequate }\end{array}$ & 5 & 443 & 3.28 & 0.97 \\
\hline $\begin{array}{l}\text { Table-II. Rank order, means and standard deviation of strengths of health facilities provided by PRSP } \\
\text { Scale: 1=S. disagree 2=Disagree 3=Somewhat agree 4=Agree 5=S. agree X=No response }\end{array}$ \\
\hline
\end{tabular}

It can be concluded that respondents were satisfied with the behaviour of staff at BHUs. However, all other aspects necessary for proper health services needed proper attention from the authorities in order to provide better health services to the needy people.

\section{Weaknesses of Health Facilities}

According to Shahid $(2010)^{13}$ health situation for women is very bleak in Pakistan. In spite of the efforts, the public sector has technical and financial restrictions which can only be complimented through the collaboration of non-profit organizations. These organizations though trying hard to provide health facilities to rural people but still there is a long way to go to achieve the required objectives. The respondents were therefore asked about the weaknesses of health services provided by PRSP. The ranking of the weaknesses of health facilities is presented in Table-III which show that statements like equipment is not in working condition (mean=2.34), staff is not available during working hours (mean $=2.23$ ), and environment of health units is not hygienic (mean=2.11) fell in between the categories of disagree and somewhat agree but tended toward disagree category and ranked 1st, 2nd, and 3rd. However, the statement like preference is given to influential people was ranked 4th with mean value 1.98 was fell in between the categories of disagree and strongly disagree but tended toward disagree.

\begin{tabular}{|c|c|c|c|c|}
\hline Weaknesses & Rank order & Weight score & Mean & Std. Deviation \\
\hline Equipment is not in working condition & 1 & 320 & 2.34 & 0.82 \\
\hline Staff is not available during working hours & 2 & 312 & 2.23 & 0.86 \\
\hline Environment of health units is not hygienic & 3 & 296 & 2.11 & 0.76 \\
\hline Preference is given to influential people & 4 & 275 & 1.98 & 0.73 \\
\hline
\end{tabular}

It can be concluded that respondents were quite satisfied with the health facilities provided by PRSP in the health units and no one agreed with the identified weaknesses.

\section{CONCLUSIONS}

It was concluded that respondents were satisfied with certain facilities like availability of female doctors in BHUs, availability of medicines and availability of competent and qualified paramedics. Provision of basic tests (blood, sugar, pregnancy and haemoglobin etc.) was very weak area which needed much improvement. It was also concluded that respondents were satisfied with the behaviour of staff at BHUs. However, provision of basic medical equipment needed attention from the authorities. It may imply that respondents were satisfied with the working of health units.

\section{RECOMMENDATIONS}

PRSP should provide more health facilities for females in rural areas. The PRSP must make arrangements for the provision of latest medical equipments to make the health units more useful. The facilities for the basic tests like sugar, blood 
etc. must be made available in the health units to make them more effective and purposeful.

Copyright@ 24 July, 2014.

\section{REFERENCES}

1. Unicef. Gender Equality. The situation of women and girls: facts and figures. Available at: www.unicef.org/ gender/index_factsandfigures.html, 2004.

2. Singh $D P$ and $M$ Singh. Women and Empowerment: Experiences from Some Asian Countries. Unistar Books. 2005.

3. WHO. Women and health: Available at: http://whqlibdoc. who.int/publications/2009/9789241563857_eng.pdf, 2009.

4. Qadri M S. Women and Development. 30 June. The Daily Times. 2006.

5. PRSP. Biennial Report. Punjab Rural Support Program. Lahore, Pakistan, 2003.

6. Shahid A. Safe motherhood: Road to realization. 09 May, The daily DAWN, 2010.

7. SOGP. Health of Women in Pakistan. Annual Report. Available at: http://www.wpfpak.org/pdfs/GBV-RH/ ResearchReports/Health\%20of\%20Women\%20in\%20
Pakistan\%20SOGP\%20Annual\%20Report\%202009.pdf, 2009.

8. White F. Assessment of Health Status and Trends in Pakistan. Available at: http://www.aku.edu/chs/pdf/ healthsituationandtrend-pakistan,2001.pdf, 2001.

9. ADB. Women's Health Project. 1999. Investing in Women's Health: Delivering Better Health Care to All. 1999.

10. Batool Z, A Afzal and S Hussain. Perceptions of the Beneficiaries of Basic Health Units in Rural Areas. J. Agri. \& Soc Sci. 1(1)-62-63. Available at: http://www. ijabjass.org, 2005

11. Chaya N. Poor Access to Health Services: Ways Ethiopia is Overcoming it. Research Commentary. Available at: http://www.populationaction.org/ Publications/Working_Papers/Poor_Access_to_Health_ Services_in_Ethiopia/Health_Servicēs.pdf, $200 \overline{7}$.

12. Jones S. Fighting a Health Crisis. The Medical Aid Foundation. Available at: http://www.maf.com.pk/ articles-33.htm, 2008.

13. Kazmi A. Women Health Status in Pakistan. Chowrangi, Pakistan politics, current affairs, business and lifestyle. Available at: http://www.chowrangi.com/women-healthstatus-in-pakistan.html, 2008.

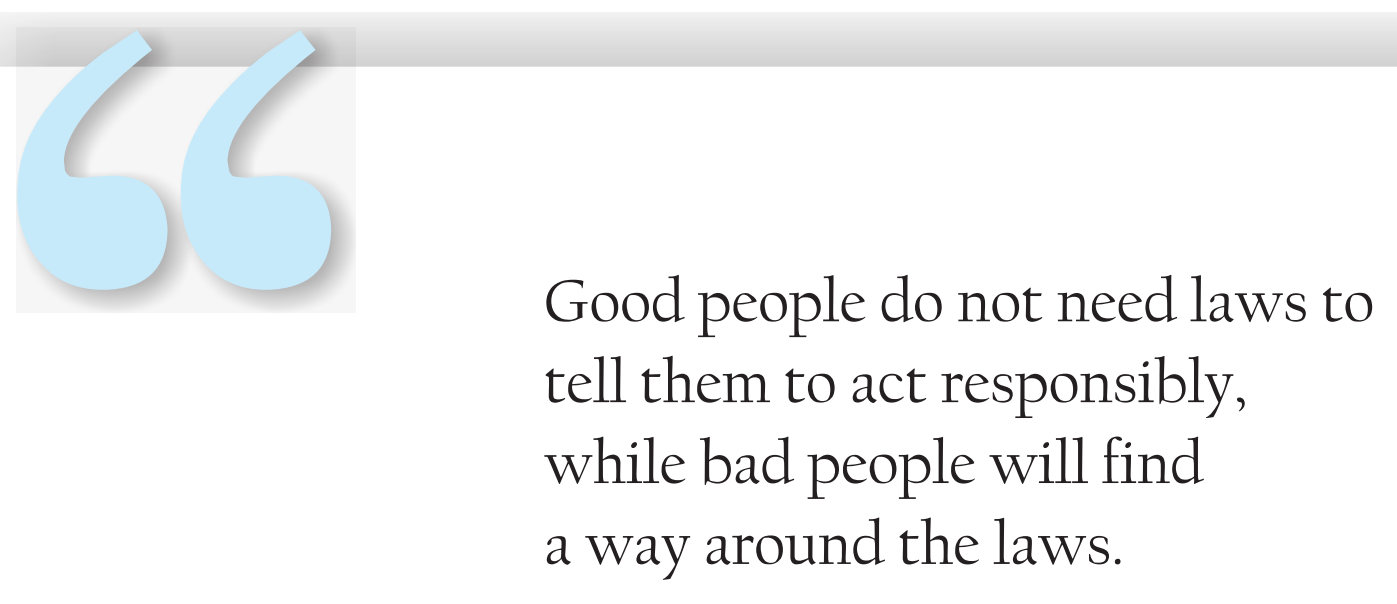

Plato (427-347 B.C.) 